\title{
POSSIBILIDADES DA PRÁTICA AVALIATIVA NO ENSINO SUPERIOR: UMA EXPERIÊNCIA COLABORATIVA
}

\author{
POSIBILIDADES DE LA PRÁCTICA EVALUATIVA EN LA ENSEÑANZA \\ SUPERIOR: UNA EXPERIENCIA COLABORATIVA
}

\author{
REFLECTIONS ON EVALUATIVE PRACTICE IN HIGHER EDUCATION: AN \\ EXPERIENCE COLLABORATIVE
}

\author{
Suênya Marley Mourão BATISTA ${ }^{1}$ \\ Ivana Maria Lopes de Melo IBIAPINA ${ }^{2}$
}

RESUMO: O presente artigo aponta algumas reflexões acerca da prática avaliativa de professores do Ensino Superior gerada a partir de pesquisa realizada no âmbito de uma instituição de ensino superior privada. O objetivo deste trabalho é caracterizar as práticas avaliativas dos professores que atuam no ensino superior e colaborar no sentido de propiciar a expansão de práticas avaliativas dinâmicas. Foram utilizados como suporte teórico-metodológico os estudos de Vigotski (2007), Liberali (2008), Ibiapina (2007, 2008), Meier (2007), Campione (2002) e Hoffmann (2011). Foi realizada pesquisa de campo, de abordagem qualitativa do tipo colaborativa com 3 (três) docentes do ensino superior utilizando-se a entrevista reflexiva como instrumento de coleta de dados a fim de promover a reflexão crítica acerca das práticas avaliativas que desenvolvem. Os resultados evidenciaram o predomínio da utilização de práticas avaliativas tradicionais pelos professores e a possibilidade de realização de práticas avaliativas dinâmicas a partir da compreensão destas oportunizada pelo processo de investigação e formação.

PALAVRAS-CHAVE: Prática avaliativa. Professor. Ensino superior. Colaboração.

RESUMEN: El presente artículo presenta algunas reflexiones sobre la práctica evaluativa de profesores de la Enseñanza Superior generada a partir de una investigación realizada en el ámbito de una institución de enseñanza superior particular. El objetivo de este trabajo es caracterizar las prácticas evaluativas de los profesores que actúan en la enseñanza superior y colaborar en el sentido de promover la expansión de prácticas evaluativas dinámicas. Fueron utilizados como respaldo teórico-metodológico los estudios de Vigotski (2007), Liberali (2008), Ibiapina (2007, 2008), Meier (2007), Campione (2002) e Hoffmann (2011). Fue realizada investigación de campo, del abordaje cualitativo del tipo colaborativo con 3 (tres) docentes de la enseñanza superior utilizándose la entrevista reflexiva como instrumento de recopilación de datos con el fin de promover la reflexión crítica sobre las prácticas evaluativas que desarrollan. Los resultados evidenciaron el predominio de la utilización de prácticas evaluativas tradicionales por los profesores y la posibilidad de realización de prácticas evaluativas dinámicas desde la comprensión de ellas por medio de lo que ha sido realizado en el proceso de investigación y formación.

${ }^{1}$ Universidade Federal do Piauí - UFPI. Email: suenya @ uninovafapi.edu.b

${ }^{2}$ Universidade Federal do Piauí - UFPI. Email: ivanaibiapina@ufpi.edu.br 
PALABRAS CLAVE: Práctica evaluativa. Profesor. Enseñanza superior. Colaboración.

ABSTRACT: This article aims to reflect on the evaluation practice of higher education teachers generated from research conducted as part of a private higher education institution. The objective of this study is to characterize the assessment practices of teachers who work in higher education and collaborate in order to facilitate the expansion of dynamic assessment practices were used as theoretical and methodological support the studies of Vygotsky (2007), Liberali (2008), Ibiapina (2007, 2008), Meier (2007), Campione (2002) and Hoffmann (2011). Field research was conducted in a qualitative approach to collaborative type with 3 (three) in higher education using the reflective interview as data collection tool to promote critical thinking about assessment practices to develop. The results showed the prevalence of use of traditional assessment practices by teachers and the possibility of performing dynamic assessment practices from the understanding of these nurtured by the research and training process.

KEYWORDS: Evaluation practice. Teacher. Higher education. Collaboration.

\section{Introdução}

As práticas avaliativas realizadas no ensino superior têm se caracterizado como predominantemente tradicionais, ou seja, servem como instrumentos de medição da capacidade dos alunos em reproduzir o conteúdo transmitido pelos professores. Nesse âmbito, observa-se carência de práticas avaliativas dinâmicas, uma vez que, a ausência de formação continuada gera a falta de conhecimentos pedagógicos necessários à aplicação desse tipo de avaliação, gerando um círculo vicioso em que os professores ensinam e avaliam seus alunos como foram ensinados e avaliados.

Segundo Meier (2007), a avaliação dinâmica permite ao professor e ao aluno conhecerem suas áreas de interesse maior e formas de raciocínio mais eficazes. Esse conhecimento a respeito do desempenho do aluno está em uma dimensão muito além da nota e das provas tradicionais, auxiliando-o a observar seu próprio progresso e seu estilo de aprendizagem. Nesse sentido, a prática avaliativa dinâmica constitui-se processo de acompanhamento da aprendizagem do aluno com foco em seu potencial de mudança, avaliando-o em processo, de modo contrário ao que propõe a prática avaliativa tradicional, que se centra no produto da aprendizagem aferido em situações de teste.

Em contraste às práticas avaliativas tradicionais, Campione (2002) sugere uma proposta de avaliação dinâmica, que consiste na ênfase em avaliar os processos psicológicos implicados na aprendizagem e na mudança. No que se refere aos testes, na 
perspectiva da avaliação dinâmica, devem ser considerados pelo professor os possíveis caminhos utilizados pelos alunos para chegarem à resolução das questões, os quais podem fornecer informações úteis para o diagnóstico sobre sua situação em relação à aquisição do conhecimento testado. Assim, a avaliação dinâmica não se reduz à prova, mas acontece pelo acompanhamento das atividades realizadas pelo aluno e do seu desenvolvimento durante todo o processo de ensino-aprendizagem.

A reflexão acerca da prática avaliativa justifica-se pelo fato de serem incipientes as contribuições provenientes de pesquisas no campo da avaliação da aprendizagem no nível superior, fazendo-se necessário promover no professor o desenvolvimento de habilidades que ajudem na formação do aluno como um profissional crítico e não um mero resolutivo de problemas preconcebidos.

Diante deste panorama, desenvolvemos pesquisa de campo, de abordagem qualitativa, do tipo colaborativa, com três docentes de uma instituição de ensino superior privada com o objetivo de refletir acerca das práticas avaliativas que desenvolvem e encontrar possibilidades para a utilização da prática avaliativa dinâmica. A pesquisa do tipo colaborativa caracteriza-se pelo trabalho conjunto entre pesquisador e partícipes, por meio da negociação e compartilhamento de ideias e objetivos, de modo que a investigação desenvolve-se com atividades de pesquisa e formação com o intuito de transformar o trabalho docente e as práticas educativas.

Nesse sentido, no presente estudo a participação dos sujeitos deu-se por meio de entrevista reflexiva, que se constitui em técnica de entrevista face a face, coletiva, de maneira que o pesquisador promove um diálogo com os partícipes a fim de esclarecer, analisar e refletir conjuntamente acerca de aspectos da prática dos sujeitos, tornando-se, portanto, oportunidade de pesquisa e formação conjunta. Assim, o trabalho colaborativo desenvolveu-se por meio das entrevistas reflexivas, trazendo expansão de aprendizados e de experiências entre os docentes, pois a sua prática cotidiana não é algo imutável e o professor, ao participar de espaços que propiciem sua reflexão e formação acerca da sua prática avaliativa, pode tornar-se agente gerador de transformações, contribuindo para a aplicação de práticas avaliativas dinâmicas. Ainda que seja possível identificar a presença forte de avaliações como aferição de conhecimentos e classificação, característica das práticas avaliativas tradicionais, o professor pode refletir sobre sua ação e gerar mudanças alcançando uma prática avaliativa dinâmica.

Dessa forma, partimos das seguintes questões: Que tipo de práticas avaliativas são utilizadas pelos professores no ensino superior? De que forma as práticas 
avaliativas utilizadas pelos professores do ensino superior podem tornar-se dinâmicas? A partir destas questões, visamos na pesquisa realizada caracterizar as práticas avaliativas dos professores que atuam no ensino superior e colaborar no sentido de propiciar a expansão de práticas avaliativas dinâmicas.

\section{A prática avaliativa tradicional: formando reprodutores de conteúdos}

Segundo Saul (1999), é possível situar a avaliação dentro de duas abordagens: a quantitativa, ancorada em pressupostos metodológicos que expressam forte influência do rigor positivista; e a qualitativa, que se propõe compreender e intervir na situação de modo mais adequado. De forma geral, apesar de existirem diversas correntes e nomenclaturas para identificar as práticas avaliativas nos meios escolares, destacamos duas tendências predominantes: a classificatória e a emancipatória.

$\mathrm{Na}$ avaliação com caráter classificatório o aluno tem sua capacidade intelectual medida pela habilidade em reproduzir os conteúdos transmitidos pelo professor. Nessa perspectiva, a avaliação é mero instrumento de coleta de nota realizada apenas no final do processo de aprendizagem, a fim de medir seu produto final, sem considerar o processo de reflexão e a autonomia do indivíduo na produção desse agir. A avaliação classificatória é pautada no ensino tradicional em que se tem como base a reprodução de conteúdos, a preocupação do professor é avançar no conteúdo previsto nas unidades do livro (LUCKESI, 2006).

Dessa forma, a prática avaliativa tradicional caracteriza-se como modalidade de caráter classificatório utilizada como instrumento de poder pelos docentes para medir a capacidade dos alunos em reproduzir os conteúdos transmitidos em aula, tornando-se um meio de controle do nível cognitivo, medido pela nota obtida nos testes.

Apesar de identificada já na Idade Média e no Renascimento, a abordagem tradicional é predominantemente a abordagem mais utilizada pelos professores atualmente, mesmo que de forma inconsciente ou não assumida e mesmo sem ter como base uma teoria propriamente dita. Compreendemos que predomina essa perspectiva nas práticas avaliativas realizadas no ensino superior, em que o teste é utilizado como mecanismo para aferição de resultados, avaliando apenas a capacidade do aluno em reproduzir o conteúdo transmitido pelo professor (MIZUKAMI, 1986). 
Nesse sentido, realizou-se pesquisa de campo, de abordagem qualitativa, do tipo colaborativa, com 3 (três) professoras de uma instituição de ensino superior privada visando caracterizar as práticas avaliativas dos professores que atuam no ensino superior e colaborar no sentido de propiciar a expansão de práticas avaliativas dinâmicas. Dessa forma, tomando como base os trabalhos de Liberali (2008) e Ibiapina (2007, 2008), elegemos a pesquisa do tipo colaborativa para desenvolver este trabalho por concebê-la como modo de compreensão da realidade, considerando uma atitude reflexiva entre os partícipes e proporcionando formação mútua. A pesquisa colaborativa compreende uma atividade compartilhada de produção de conhecimentos e de desenvolvimento profissional docente, trata-se de atividade de pesquisa e formação.

Os dados apresentados são oriundos de entrevista reflexiva realizada com as professoras partícipes da pesquisa. $\mathrm{Na}$ entrevista reflexiva privilegia-se o contato direto e coletivo com os partícipes. Dessa forma, marcamos dia e horário com os partícipes, para realizarmos a entrevista reflexiva de maneira coletiva. Neste procedimento, pesquisador e partícipes escutam atentamente o discurso uns dos outros e tem liberdade para intervir, concordando ou discordando das posições expressadas. O pesquisador introduz gradualmente as questões preparadas e não se limita a gravar as respostas, mas, a partir da resposta dos partícipes, estimula novas perguntas ou debates, produzindo novas respostas, sem interrupção do fluxo de troca livre de ideias (LURIA, 1990).

Os nomes dos partícipes da pesquisa foram substituídos por P1, P2, P3 e P4, para garantir o anonimato das mesmas. A partir do trecho apresentado a seguir podemos observar aspectos de uma prática avaliativa predominantemente tradicional.

P1: Que tipo de prática avaliativa a gente realiza?

P2: Eu quase sempre faço a tradicional.

P3: A tradicional. A minha tem sido mais tradicional.

P4: A minha primeira avaliação é.

P1: E por que é tradicional?

P3: Ah, porque a gente usa mais mesmo é a questão da prova. A prova é que mostra pra gente o que esse aluno sabe.

P2: É, pra mim a escrita é o meu convencimento.

P4: Na primeira é porque eu uso mesmo só a prova, mas nas outras já faço diferente, faço várias atividades. Mas eu penso que o sistema de avaliação na graduação deveria ter uma outra cara. 
P2: Eu digo que é tradicional porque a gente faz avaliação como verificação do conhecimento adquirido pelo aluno, é o que a gente faz.

A professora P1 questiona o grupo a fim de que cada partícipe caracterize sua prática avaliativa. P2 e P3 confirmam que realizam uma prática avaliativa tradicional. P4 admite que realiza a prática avaliativa tradicional apenas no primeiro momento de avaliação. Logo em seguida, P1 questiona as outras professoras para que justifiquem o motivo de compreenderem que realizam uma prática avaliativa tradicional.

A professora $\mathrm{P} 3$ pontua em seu discurso a utilização predominante da prova para a verificação do que "esse aluno sabe". Dessa forma, a prática avaliativa da professora P3 caracteriza-se como predominantemente tradicional, tendo em vista o aspecto de centrar-se na prova como instrumento capaz de aferir o conhecimento do aluno.

A avaliação tradicional pressupõe uma determinação de medida da capacidade intelectual de um indivíduo com base no desempenho em situação de teste. Os testes pressupõem a existência de características mensuráveis no sujeito, que se desenvolvem de maneira previsível. A professora P2 confirma a posição de P3 ao proferir que "a escrita é meu convencimento". Nesse discurso, P2 demonstra que valoriza a prova enquanto meio hábil a fornecer-lhe as informações necessárias para formar seu convencimento sobre o conteúdo aprendido pelo aluno.

No final do diálogo apresentado, P2 corrobora a modalidade avaliativa tradicional ao caracterizar sua avaliação como "verificação do conhecimento adquirido pelo aluno" e finaliza "é o que a gente faz". Dessa forma, a prática avaliativa da professora P2 também se caracteriza como predominantemente tradicional, pois a avaliação centra-se no produto, tornando-se instrumento de coleta de nota realizado apenas no final do processo de ensino-aprendizagem a fim de medir seu produto final sem considerar o processo de reflexão autônoma (BEHRENS, 2010).

A professora P4 confirma que realiza a prática avaliativa tradicional em seu primeiro momento avaliativo e assim entende porque se utiliza apenas da prova como instrumento avaliativo. No entanto, a docente destaca que se afasta da perspectiva tradicional, pois utiliza outras atividades para a avaliação do aluno e não somente o teste. Assim, a professora P4 revela consciência desta situação e demonstra o desejo de mudança, uma vez que já se afasta da perspectiva tradicional, realizando atividades diversas e não apenas a prova. $\quad$ Compreendemos que a prática avaliativa de P4 caracteriza-se como predominantemente dinâmica, tendo em vista que, nessa 
perspectiva, a prática avaliativa visa atingir não só o conhecimento já adquirido ou acumulado, expresso pelo desempenho nos testes, entendido como produto consolidado, mas, principalmente, os indicadores de potencial de aprendizagem do indivíduo identificados em diversas situações ao longo do processo de ensino-aprendizagem (LINHARES, 1995).

Dessa forma, por meio da reflexão crítica instrumentalizamos o pensar e o agir das professoras para que, conscientes da postura metodológica que assumiram, considerassem as possibilidades de transformação da mesma. $O$ trecho a seguir apresenta processo de reflexão crítica desenvolvido com as partícipes para que apresentassem a finalidade da prática avaliativa tradicional e formas de melhorar a prática avaliativa que realizam.

P1: Qual a finalidade da nossa prática avaliativa?

P4: A minha finalidade, a finalidade sempre é isso que eu digo, eu faço uma abordagem de todo o conteúdo então eu quero ver se eles fixaram o que eu disse. [...] a finalidade das minhas práticas eu penso que estou fazendo dessa forma pra que eles vivenciem o processo, pra que eles participem das aulas, pra que eles questionem.

P2: O que eu quero é saber se eles lembram do que eu disse, se eles lembram do que eu abordei, se fixou o que eu tava conversando na sala de aula, né?

P1: E em que poderíamos melhorar nossa prática avaliativa?

P4: Em mecanismos de assim, não digo compreensão, mas mecanismos que agilizem a forma pragmática mesmo do sistema.

P2: Acho que fazendo mais essa prática avaliativa dinâmica, não é? Agora como eu não sei. Eu queria mesmo era uma forma de avaliar que não precisasse fazer prova, nem corrigir [risos]. Que eu fizesse um processo avaliativo sempre e que eu não precisasse fazer prova. Eu acho prova cruel prova é tenso, prova estressa, prova existe o decoreba, prova [diz batendo na mesa], prova é uma coisa terrível!

P3: É verdade. A prática avaliativa é necessária, mas a gente poderia tentar buscar novos meios.

P2: O problema são esses meios porque eu não sei.

Ao serem questionadas com o objetivo de informarem acerca da finalidade de suas práticas avaliativas, P4 inicia respondendo "eu quero ver se eles fixaram o que eu disse". Embora essa afirmação demonstre a característica pontual de uma prática avaliativa tradicional, a prova como instrumento de averiguação do conhecimento do aluno, a professora destaca que sua prática avaliativa tem a finalidade de fazer com que 
os alunos vivenciem o processo de aprendizagem e sejam questionadores, evidenciando uma prática avaliativa dinâmica.

P2 confirma a predominância da prática avaliativa tradicional demonstrando a finalidade de absorção de conteúdo pelo aluno. O discurso da partícipe revela situações hierárquicas em que exige dos alunos a reprodução e a memorização do conteúdo abordado em aula "se eles se lembram do que eu abordei, se fixou o que eu tava conversando". Nessa perspectiva, segundo Lunt (2003), considera-se frequentemente que o resultado da avaliação fornece uma caracterização do que foi aprendido pelo indivíduo. Dessa conclusão resulta a nota que reflete a capacidade intelectual geral do aluno. Apoiando-se na abordagem avaliativa baseada puramente no produto, deixa-se de observar os processos implicados na aquisição desses produtos.

No questionamento "Em que poderíamos melhorar nossa prática avaliativa?”, as partícipes são conduzidas à reconstrução de suas práticas avaliativas. P4 pontua a necessidade de superar o aspecto pragmático do sistema em que está inserida, que exige as "notas" para avaliar os alunos e demonstra a vontade de perceber o desenvolvimento dos alunos por meio da "conversa", evidenciando a vontade de realizar prática avaliativa em que pudesse acompanhar os alunos.

P2 revela que "queria mesmo era uma forma de avaliar que não precisasse fazer prova nem corrigir" e pontua "eu acho prova cruel, prova é tenso, prova estressa". P3 confirma o discurso de $\mathrm{P} 2$ e diz que a prática avaliativa é necessária, mas que é preciso buscar novos meios de realizá-la. Assim também acredita P2 e frisa não ter conhecimento de que meios usar para mudar a prática que desenvolve.

A ênfase na informação do produto resulta na tendência de supor que possuir este dado é equivalente a mensurar a competência do aluno dentro da disciplina. No entanto, essa perspectiva gesta a crescente conscientização dos educadores acerca dos problemas inerentes aos procedimentos de avaliação estática tradicional, no que diz respeito a suas funções, fazendo com que a avaliação dinâmica ganhasse destaque no cenário educacional como modalidade avaliativa que permite a avaliação de processos, mais do que produtos de aprendizagem. As partícipes corroboram esse entendimento, como podemos observar quando P2 aduz que necessitam encontrar novos meios de realizar a prática avaliativa, que esta pudesse ser um "processo sempre".

Utilizando-nos dos procedimentos propostos na e pela Pesquisa Colaborativa oportunizamos às partícipes espaço de formação em que refletiram criticamente sobre suas práticas avaliativas, de maneira que foram concebidas não apenas como objetos de 
análise, mas como sujeitos cognoscentes que contribuíram para a coprodução de conhecimentos. Dessa forma, a pesquisa realizada efetivou-se como prática que se voltou para a compreensão dos problemas vivenciados no ensino superior, especialmente no que tange às práticas avaliativas, contribuindo com a possibilidade de transformação dos contextos de atuação e formação docente das partícipes.

Nesse sentido, faz-se necessário ao docente do ensino superior a reflexão crítica que possibilite a superação da "educação bancária" e da postura docente opressora que ampara a prática avaliativa tradicional, por uma postura na qual aluno e professor tornam-se sujeitos ativos no processo de ensino-aprendizagem (FREIRE, 1987).

Dessa forma, a concepção avaliativa emancipatória propicia a realização de práticas avaliativas dinâmicas, uma vez que transforma a função do docente que atua como mero repassador de conteúdos, permitindo sua interação ativa com o aluno e transformando-o em guia, orientador, instigador e motivador nas atividades de avaliação.

Assim, discutimos com as partícipes da pesquisa acerca das práticas avaliativas dinâmicas que seriam instrumento para suprir as necessidades das mesmas no que tange ao processo avaliativo. É sobre as práticas avaliativas dinâmicas que dialogaremos a seguir.

\section{Prática avaliativa dinâmica: rompendo a avaliação tradicional pelo trabalho colaborativo}

Observando a historicidade das práticas avaliativas na seção anterior, compreendemos que estas práticas foram dominadas ao longo dos anos pelo paradigma tradicional derivado de uma tradição positivista e reducionista. Destarte, as práticas avaliativas caracterizaram-se pelo caráter "estático", ou seja, a avaliação reduziu-se aos testes, priorizando o produto da aprendizagem, aquilo que o aluno é capaz de reproduzir do que foi ensinado pelo professor, em detrimento de um processo avaliativo realizado durante a relação de ensino-aprendizagem.

O objetivo da avaliação dinâmica seria o de avaliar em mais detalhes a aprendizagem dos alunos observando-as no cotidiano da sala de aula. Assim, o professor teria como objetivo descrever as competências manifestadas pelos alunos em situação de testagem e que serviriam como base para a elaboração de atividades de aperfeiçoamento. 
$\mathrm{Na}$ avaliação dinâmica, tem-se a aproximação e envolvimento do professor no processo de ensino-aprendizagem com foco na atuação do estudante. Nessa perspectiva avaliativa o professor acompanha o aluno observando suas dificuldades na aprendizagem e colabora com aquele no sentido de auxiliá-lo a superar tarefas que sozinho não conseguiria resolver. De acordo com Meier (2007, p.130-131):

\begin{abstract}
A Avaliação Dinâmica está baseada na crença de que o ser humano é "altamente plástico", isto é, tem a capacidade, o potencial de modificar-se. Esse olhar é diferente do olhar da escola. Enquanto a escola está preocupada com o nível de funcionamento real, observável do sujeito, a avaliação dinâmica está centrada na possibilidade desse sujeito de aprender, de modificar-se, de aprender a aprender. A avaliação é denominada "dinâmica", pois avalia o sujeito de forma não estática, pontual. Avalia seu modus operandi, na trajetória entre o não aprendido ao aprendido. Muito mais que uma lista de conteúdos aprendidos, a avaliação dinâmica possibilita ao professor conhecer quais de suas interferências possibilitaram insights ao aluno. Mais do que uma nota pelo conjunto de tarefas resolvidas, a avaliação dinâmica quer saber por que razão uma ou outra tarefa não foi possível de ser resolvida e, principalmente, como ajudar esse aluno a resolver tais tarefas, consideradas a princípio difíceis.
\end{abstract}

Essa modalidade avaliativa vem sendo desenvolvida desde a década de 1970, a partir dos trabalhos de Reuven Feuerstein e seus colaboradores, insatisfeitos com os métodos de avaliação tradicionais. A ideia de avaliação dinâmica desenvolveu-se a partir de concepções teóricas sobre a plasticidade da cognição humana e da necessidade de encontrar novos meios de avaliar os alunos que não se reduzissem apenas às provas (LINHARES, 1995).

A prática avaliativa dinâmica visa atingir não só o conhecimento já adquirido ou acumulado, expresso pelo desempenho nos testes entendido como produto consolidado, mas, principalmente, os indicadores de potencial de aprendizagem do indivíduo identificados em diversas situações ao longo do processo de ensino-aprendizagem. A perspectiva avaliativa dinâmica permite ao professor acompanhar o aluno e observar suas necessidades com a finalidade de garantir o fornecimento de ajuda, melhorando as condições da avaliação para que o examinando possa atingir grau crescente de autonomia em situações de aprendizagem (LINHARES, 1995).

A avaliação dinâmica, conforme Campione (2002), possui três dimensões: foco, interação e alvo.

O foco refere-se às diferentes formas pelas quais o potencial de mudança está sendo avaliado, isso se dá utilizando-se procedimento de teste-ensino-reteste, ou pela 
observação contínua do aluno em seus processos envolvidos na aprendizagem e na mudança. Por exemplo, os alunos podem ser avaliados em uma tarefa ou teste específico, logo após recebem alguma prática ou instrução e, subsequentemente, são testados novamente para verificar o aperfeiçoamento ou a receptividade em relação à instrução. O número de pontos obtidos indica aperfeiçoamento ou mudança e poderia ser pensado como indicador do potencial de aprendizagem e para entender os processos nela envolvidos.

A interação refere-se ao tipo de envolvimento entre aluno e professor. Brown e Campione (1986) sugerem a realização de entrevistas com o objetivo de produzir dados que possam ter propriedades prognósticas. Pretende-se que estes dados demonstrem a situação do aluno, a natureza do aperfeiçoamento necessário ou a quantidade de ajuda necessária para dominar um determinado conteúdo ou ter sucesso em determinada tarefa. A ideia é que a análise destas entrevistas forneça mais informações sobre os indivíduos do que os testes estáticos.

O alvo refere-se ao tipo de habilidades que estão sendo levadas em conta no processo avaliativo. A avaliação dinâmica visa o desenvolvimento de competências gerais e não apenas o domínio do aluno em uma área específica.

Destaca-se que, na avaliação dinâmica não há o incentivo à competição entre os alunos ou a comparação entre pares, tendo em vista que o indivíduo é comparado com ele mesmo em diversos momentos do processo de ensino-aprendizagem. Nesse sentido, o sujeito é o seu próprio controle durante o processo avaliativo.

Dessa forma, na entrevista reflexiva realizada com as professoras do ensino superior, visamos possibilitar às mesmas a vivência de uma situação colaborativa que ensejasse a reflexão crítica acerca das práticas avaliativas dinâmicas para que pudessem compreender a finalidade desta prática.

P1: Qual seria a finalidade de uma prática avaliativa dinâmica?

P2: A gente determina o momento de avaliar, mas eu entendo que a gente precisa de mais de um momento de avaliação mesmo, essa avaliação deveria ser uma coisa mais dinâmica, mais contínua, mais constante.

P3: Eu acho que é a questão de tentar outros meios de prática avaliativa, só que às vezes a gente não consegue. Eu tento fazer um trabalho, tento avaliar de forma diferente pra avaliar o conceito, porque eu percebo muitas vezes no convívio com os alunos que nem sempre aquela prova corresponde ao que ele de fato conseguiu. 
P4: Então, é a questão de que os alunos não estão ali só pra fazer prova, mas estão ali pra se formarem, pra serem bons profissionais, mais humanizados. É questão de saber que o indivíduo tem suas experiências, suas vivências e no momento que ele tá atuando ele é um ser humano, ele deve pensar no outro, se colocar no lugar do outro, perceber o mundo, perceber como as relações se estabelecem e isso a gente não aprende só lendo o código, a gente aprende com as vivências.

P1: E que cidadão a gente forma quando avalia de maneira dinâmica?

P4: Acho que uma pessoa melhor. Pela experiência que eu tenho eu vejo que forma um cidadão consciente, crítico. Eu tive uma aluna que não gostava, não queria aceitar quando eu fazia essa forma de avaliação, ela criou uma resistência comigo. No final do semestre ela chegou pra mim e me convidou pra ser orientadora dela no TCC, disse que no decorrer do processo ela compreendeu o que eu queria dela. Aquilo foi muito marcante pra mim e certamente ela se tornou uma pessoa melhor, passou a ver a sociedade de uma forma mais crítica. Acho que seriam alunos e profissionais que vivenciaram o processo de ensino-aprendizagem, questionadores, que refletem, que tem despertado o senso crítico.

P2: Forma um profissional ético, com senso crítico, é isso. Eu procuro não só passar informação, mas discutir com eles também pra gerar esse senso crítico, né? Eu tento mostrar que ali não é só um conteúdo no livro, mas que tem ligação direta com a realidade, esse vínculo pra gerar o senso crítico.

P3: É isso mesmo.

P2, ao ser questionada, inicia utilizando a expressão "a gente", o que indica ação realizada pelo grupo, revelando que existe momento determinado para a realização da avaliação. A partícipe revela a necessidade em mudar a situação de haver um momento determinado para avaliar.

No discurso de P3, evidencia-se a tentativa em realizar forma diferente de avaliação e demonstra seu posicionamento de não acreditar que somente a prova possa revelar aquilo que o aluno de fato conseguiu aprender. A prática avaliativa dinâmica foca não somente naquilo que o aluno já conseguiu aprender, mas em como ele aprende, facilitando assim a compreensão do professor quanto ao potencial do aluno e às suas funções que estão em desenvolvimento.

A partícipe P4 apresenta a compreensão de que a avaliação dinâmica propicia não apenas a formação de bons profissionais, mas contempla o aspecto humano na formação do aluno, ressaltando a importância de suas vivências para a constituição do próprio sujeito. As vivências em sala de aula possibilitam a contínua transformação do indivíduo pelas relações que estabelece com colegas e professores. O par mais 
experiente fornecerá a colaboração necessária para que o aluno compreenda determinado conteúdo e possa desenvolver funções até então em amadurecimento. A partícipe destaca ainda a necessidade da superação da racionalidade técnica, que, segundo Libâneo (1993), baseia-se na transmissão de conteúdos pelo professor utlizando-se de testes para verificar se os alunos aprenderam o conteúdo. A partícipe revela o interesse na superação desse paradigma e compreende a finalidade da prática avaliativa dinâmica, bem como sua importância nesta superação.

A partir do discurso das partícipes, interpretamos que P2 e P3 compreendem a importância da realização de uma prática avaliativa dinâmica, no entanto, ainda não tem conhecimento de como realizar essa modalidade avaliativa. A partícipe P4 revela compreensão da importância da prática avaliativa dinâmica, embasando seu posicionamento nas vivências em sala de aula e na necessidade de superação do paradigma da racionalidade técnica.

P4 enfatiza sua credibilidade de que a prática avaliativa dinâmica forma um cidadão consciente e crítico. A partícipe destaca a vivência do processo de ensinoaprendizagem possibilitando aos alunos o questionamento e a reflexão que despertam o senso crítico. A prática que forma para a cidadania, segundo Liberali (2008), é aquela em que o docente desenvolve prática reflexiva e crítica de maneira intencional e consciente, comprometendo-se com a formação de sujeitos críticos, comprometidos com a transformação da sociedade em que vivem. A prática avaliativa dinâmica inserese nesta perspectiva, uma vez que não apenas prepara o aluno para assumir postos de trabalho na sociedade, mas visa o desenvolvimento do aluno enquanto cidadão atento às necessidades do contexto sócio-histórico em que se insere.

P2 entende a importância da prática avaliativa dinâmica na formação de profissional ético que tenha desenvolvido seu senso crítico. Apesar de referir-se inicialmente apenas ao aspecto profissional da formação, a partícipe revela que tenta instigar o senso crítico do aluno relacionando o conteúdo do livro à realidade em que vive.

Dessa forma, a reflexão ocorrida na entrevista reflexiva realizada com as professoras possibilitou o entendimento da finalidade das práticas avaliativas dinâmicas, bem como a compreensão de como vem sendo desenvolvidas e a relevância das mesmas na formação do aluno. A compreensão das práticas a partir do contexto sócio-histórico em que se realizam permite, segundo Smyth (1992), que as ações desenvolvidas pelas partícipes sejam mais conscientes, possibilitando-as compreender suas práticas 
avaliativas frente a questões sociais e históricas mais amplas, e não somente averiguar o que funcionou ou não.

Diante das possibilidades de atuação para a prática avaliativa das partícipes visamos conduzir o processo de reflexão crítica de modo a alcançar o planejamento de mudanças na avaliação realizada pelas professoras, concebendo novas possibilidades de fazer.

\section{Caminhos para a materialização das práticas avaliativas dinâmicas no ensino superior}

A partir da compreensão das práticas avaliativas dinâmicas, é necessário refletir acerca de ações que possam ser desenvolvidas no âmbito do ensino superior para que estas práticas se materializem. $\mathrm{Na}$ entrevista reflexiva realizada com as professoras, discutimos acerca destas ações de forma que mudanças qualitativas ocorressem no agir avaliativo, gerando possibilidade de transformação das práticas até então realizadas pelas partícipes.

P1: Que ações poderíamos desenvolver pra tornar a prática avaliativa dinâmica possível?

P4: Planejar, planejar.

P2: Bom, algo que eu parei muito pra pensar e vi que talvez esteja fazendo assim e pretendo continuar é a questão do foco, que seria o teste-ensino-reteste. Eu faço um ensino e depois uma pré-prova e outra prova e aí eu já consigo avaliar o crescimento, o desenvolvimento dele.

P3: Pode até ser assim, em um primeiro momento questionar os alunos, que é o prognóstico pra saber o nível deles, depois fazer o ensino e depois a prova.

P2: É, eu faço isso.

P1: Mas você consegue fazer essa atividade antes da prova e visualiza esse desenvolvimento da atividade para a prova?

P2: Sim, é assim que eu consigo fazer e também eu já vou observando o desenvolvimento do aluno.

No trecho apresentado, P1 incentiva as partícipes a apresentarem ações para a materialização das práticas avaliativas dinâmicas no contexto em que atuam. P4 repete o "planejar" como ação concreta. 
P2 destaca a ação do teste-ensino-reteste, apresentada por Campione (2002) quando caracteriza uma das dimensões da prática avaliativa dinâmica: o foco. Segundo o autor, o foco diz respeito ao nível de mudança observado no processo de realizar um teste prévio como prognóstico, como destaca P3, em seguida ocorre o oferecimento de uma instrução pelo professor e após realiza-se um novo teste para verificar a mudança ocorrida ou a relevância da maneira como a instrução se apresentou. Dessa forma, o professor pode realizar o acompanhamento do aluno observando os processos envolvidos na aprendizagem e na mudança.

Ao ser questionada por P1 acerca da sua observação do desenvolvimento do aluno, P2 revela que consegue realizar as três etapas (teste-ensino-reteste) da prática avaliativa dinâmica e destaca que faz o acompanhamento do aluno.

A reflexão crítica realizada nos trechos das discussões com as professoras possibilitou, por meio dos questionamentos e reflexões, que as partícipes compreendessem as ações que realizam e pudessem transformá-las. Nesse sentido, Liberali (2008, p. 38) destaca que:

A reflexão crítica implica a transformação da ação,ou seja,
transformação social. Não basta criticar a realidade, mas mudá-la, já
que indivíduo e sociedade são realidades indissociáveis. Assumir uma
postura crítica implica ver a identidade dos agentes como intelectuais
dentro da instituição e da comunidade, com funções sociais concretas
que representam formas de conhecimento, práticas de linguagem,
relações e valores sociais que são seleções e exclusões particulares da
cultura mais ampla. Observamos que existem as seguintes predominâncias: a prática avaliativa de P2 e P3 caracteriza-se como predominantemente tradicional, no entanto revela elementos da prática avaliativa dinâmica, por exemplo, a necessidade de acompanhar o desenvolvimento do aluno durante o processo de ensino-aprendizagem. A prática avaliativa de P4 caracteriza-se como predominantemente dinâmica, entretanto, utiliza a prova como meio de percepção de aprendizagem por parte do aluno. Constatamos também que as modalidades de avaliação tradicional e dinâmica não se apresentam puramente, mas se revelam na prática das partícipes agregando características ora de uma, ora da outra.

Concebemos a relevância da avaliação dinâmica enquanto modalidade de caráter emancipatório capaz de promover o desenvolvimento cognitivo do aluno, especificamente do aluno de ensino superior, vez que nesse nível de ensino as práticas avaliativas têm tornado-se apenas um meio de preparar os estudantes para provas e 
concursos, valorizando tão somente os procedimentos de avaliação que "valem nota". Minick (1987) sugere que todos aqueles que participam do movimento de avaliação dinâmica reconheçam a necessidade de desenvolver mecanismos de avaliação que ofereçam: medidas diretas do potencial de aprendizagem e desenvolvimento do sujeito, informações sobre os processos que levam ao sucesso ou ao fracasso do sujeito na execução de tarefas cognitivas e informações sobre o que poderia ser feito para facilitar a educação e o desenvolvimento do mesmo.

\section{Considerações Finais}

Observamos que as partícipes compreenderam e compartilharam do significado de prática avaliativa dinâmica, que consiste na ênfase em avaliar os processos psicológicos implicados na aprendizagem e na mudança, observando em mais detalhes a aprendizagem dos alunos. Dessa forma, identificamos os sentidos internalizados pelas partícipes, viabilizando processo reflexivo que contribuiu para o compartilhamento de significados, oportunizando, assim, significativas mudanças em suas práticas avaliativas.

A pesquisa atingiu ao objetivo proposto, uma vez que pudemos caracterizar as práticas avaliativas dos professores que atuam no ensino superior como predominantemente tradicionais e, a partir das discussões promovidas nas entrevistas reflexivas, colaboramos no sentido de propiciar a expansão de práticas avaliativas dinâmicas, pois se observou nos discursos das partícipes a compreensão do significado das práticas avaliativas dinâmicas, revelando-se a possibilidade de aplicá-las em suas práticas.

Esta pesquisa-formação tornou-se oportunidade de formação para as partícipes, pois compreenderam suas práticas avaliativas e revelaram em seus discursos que passaram a conhecer novas formas de avaliação, considerando a dinamicidade do processo avaliativo e a necessidade de acompanhar o desenvolvimento do aluno por meio de situações diversas em sala de aula e não somente por meio da prova, gerando possibilidade de transformação das práticas que realizavam antes da pesquisa.

No campo social, a pesquisa trouxe expansão dos conhecimentos acerca das práticas avaliativas no ensino superior e apresentou possibilidades de transformação destas, por meio da compreensão de novas formas de avaliação identificada no discurso 
dos partícipes. A investigação favoreceu o repensar das práticas avaliativas utilizadas pelos professores do ensino superior, investigando a presença do aspecto dinâmico destas avaliações e propiciando maneiras de torná-lo mais presente por meio de reflexões compartilhadas colaborativamente entre os docentes, resultando numa perspectiva de melhoria da qualidade do ensino.

\section{REFERÊNCIAS}

BEHRENS, M. A. O Paradigma Emergente e a Prática Pedagógica. 4. ed. Petrópolis, RJ: Vozes, 2010.

BROWN, A. L.; CAMPIONE, J. C. Psychological theory and the study of learning disabilities. American Psychologist, New Jersey, v. 41, n. 10, p. 1059-1068, Out. 1986.

CAMPIONE, J. C. Avaliação Assistida: uma taxonomia das abordagens e um esboço de seus pontos fortes e fracos. In: DANIELS, Harry (Org.). Uma introdução a Vygotsky. São Paulo: Edições Loyola, 2002. p. 255-292.

FREIRE, P. Pedagogia do oprimido. 14. ed. Rio de Janeiro: Paz e Terra, 1987.

HOFFMANN, J. Avaliação mediadora. 31. ed. Porto Alegre: Editora Mediação, 2011.

IBIAPINA, I. M. L. de M. (Org.). Formação de professores: texto \& contexto. Belo Horizonte: Autêntica, 2007.

IBIAPINA, I. M. L. de M. Pesquisa Colaborativa: investigação, formação e produção de conhecimentos. Brasília: Liber Livros, 2008.

LIBÂNEO, J. C IBIAPINA, I. M. L. de M. Tendências Pedagógicas na prática escolar. Revista da Associação Nacional de Educação, São Paulo, n.3, p.11-19, 1993.

LIBERALI, F. C. Formação critica de educadores: questões fundamentais. Taubaté, SP: Editora Universitária, 2008

LINHARES, M. B. M. A Avaliação Assistida: fundamentos, definição, características e implicações para a Avaliação Psicológica. Psicologia:teoria e pesquisa, Brasília -DF, v. 1, n. 11, p. 23-31, jan./abr. 1995.

LUCKESI, C. C. Avaliação da aprendizagem escolar: estudos e proposições. 18. ed. São Paulo: Cortez, 2006.

LUNT, I. A prática da avaliação. In: DANIELS, H. (Org.). Vygotsky em foco: pressupostos e desdobramentos. 6. ed. Campinas: Papirus, 2003. p. 219-254.

LURIA, A. R. Desenvolvimento Cognitivo. São Paulo: Ícone, 1990. 
MEIER, M. Mediação da aprendizagem: contribuições de Feuerstein e de Vygotsky. Curitiba: Edição do Autor, 2007.

MINICK, N. Implications of Vygotsky's theories for dynamic assessment. In: LIDZ, C. S. Dynamic assessment: an interactional approach to evaluating learning potential. Nova York: Guilford Press, 1987. p. 169-184.

MIZUKAMI, M. das G. Ensino: as abordagens do processo. São Paulo: EPU, 1986.

SAUL, A. M. Para mudar a prática de avaliação do processo ensino-aprendizagem. In: BICUDO, V. M. A.; SILVA JUNIOR, C. A. (Org.). Formação do educador e avaliação educacional: conferências, mesas-redondas. v. 1. São Paulo: Editora UNESP, 1999. p. 67-77.

SMYTH, J. Teacheres Work and the politics of reflection. American Educational Research Journal, v. 29, n. 2, p. 267-300, 1992.

VIGOTSKI, L. S. A Formação Social da Mente. 7. ed. São Paulo: Martins Fontes, 2007.

\section{Como referenciar este artigo}

BATISTA, Suênya Marley Mourão.; IBIAPINA, Ivana Maria Lopes de Melo. Possibilidades da prática avaliativa no ensino superior: uma experiência colaborativa. Revista Ibero-Americana de Estudos em Educação, Araraquara, v. 11, n. 4, p. 19942011, 2016. Disponível em: 〈http://dx.doi.org/10.21723/riaee.v11.n4.7392>. E-ISSN: 1982-5587.

Submetido em: novembro/2014

Aprovação final em: novembro/2016 